\title{
Seropositive bucks and within-herd prevalence of small ruminant lentivirus infection
}

\author{
DOROTA NOWICKA', MICHAE CZOPOWICZI', OLGA SZALUŚ-JORDANOW², \\ LUCJAN WITKOWSKI ${ }^{1}$, EMILIA BAGNICKA ${ }^{3}$, JAROSŁAW KABA ${ }^{l}$ \\ ${ }^{1}$ Laboratory of Veterinary Epidemiology and Economics, Faculty of Veterinary Medicine, Warsaw University of Life Sciences, Warsaw, \\ Poland \\ ${ }^{2}$ Division of Infectious Diseases, Department of Small Animal Diseases with the Clinic, Faculty of Veterinary Medicine, Warsaw University \\ of Life Sciences, Warsaw, Poland \\ ${ }^{3}$ Institute of Genetics and Animal Breeding, Polish Academy of Sciences, Jastrzębiec, Poland
}

\begin{abstract}
Caprine arthritis-encephalitis is an economically important disease of goats. It is evident that horizontal transmission through respiratory secretions and milk plays an important part in the disease spread whereas the role of sexual transmission remains questionable. The cross-sectional study was carried out to investigate the relationship between presence of small ruminant lentivirus (SRLV)-seropositive bucks and seroprevalence of SRLV infection in does in herds. The analysis included 76 goat herds seropositive for SRLV infection. A sample of adult female goats from each herd was selected in a simple random fashion. All males present in a herd were also enrolled in the study. The animals were screened with commercial serological immunoenzymatic tests. Standardized questionnaires were used to gather knowledge of 3 hypothesized herd-level confounding factors: number of years for which a herd had existed until testing, goat replacement from other herds in Poland and use of machine milking. Three-level hierarchical linear regression model was developed to evaluate the relationship $(\alpha=0.05)$. Median (interquartile range) within-herd seroprevalence of SRLV was $60.1 \%$ (35.7\% to $87.9 \%$ ) and $35.8 \%$ (10.1\% to $49.6 \%$ ) in herds where seropositive males were present and absent, respectively. Controlling for possible confounders presence of SRLV-seropositive bucks proved to be an independent factor linked to the higher within-herd seroprevalence of SRLV $(p=0.001)$. The study indicates that seropositive bucks may facilitate the spread of SRLV infection in goat herds and therefore their presence should be considered as a risk factor.
\end{abstract}

Key words: SRLV, CAE, lentivirus, sexual transmission, goat.

(Cent Eur J Immunol 2015; 40 (3): 283-286)

\section{Introduction}

Small ruminant lentivirus (SRLV) is a group of retroviruses (Family Retroviridae, Genus Lentivirus) that infect sheep, goats and are responsible for causing maedi-visna disease in sheep and caprine arthritis-encephalitis (CAE) in goats.

Although SRLV mainly spreads vertically through the ingestion of contaminated colostrum and milk, it is evident that horizontal transmission plays an important role in the spread of CAE regardless of a goat's age $[1,2]$. In herds where kids are fed only with virus-free milk, it was found that the within-herd incidence of SRLV-infection increased, indicating horizontal transmission [3-5]. The two main horizontal routes of transmission are via respiratory secretions
[6] and milk [7, 8] as both the lungs and the udder are target organs for SRLV infection. Sexual transmission is possible but has not been proven. There are no reports of infection of does by SRLV-positive bucks through natural mating, but infection of does by artificial insemination with SRLV positive semen has been confirmed [9]. SRLV nucleic acid has been identified in the seminal fluid, non-spermatic cells and preputial swabs of bucks [10-13]. Two studies imply that SRLV-infected bucks play an important role in horizontal SRLV transmission. Truchetti et al. [14] demonstrated not only RNA and proviral DNA of SRLV but also expression of viral antigens in most of the organs of the reproductive tract of naturally infected bucks. Al Ahmad et al. [15] showed that goat uterine epithelial cells were susceptible to SRLV infection in vivo.

Correspondence: Jarosław Kaba, Laboratory of Veterinary Epidemiology and Economics, Faculty of Veterinary Medicine, Warsaw University of Life Sciences, Nowoursynowska 159 C, 02-776 Warsaw, Poland, tel. +48 2259361 11, e-mail: jaroslaw_kaba@sggw.pl 
A cross-sectional study was carried out to investigate the relationship between presence of SRLV-seropositive bucks and seroprevalence of SRLV infection in does in herds.

\section{Material and methods}

The sampling frame included 76 goat herds which tested positive for SRLV infection between 1996-2014. The size of the herds ranged from 10 to 600 adult females with a median of 60 (interquartile range 30 to 115). A simple random sample of adult female goats from each herd was selected to allow detection of at least one seropositive animal at the expected within-herd seroprevalence of $10 \%$ and $95 \%$ confidence level [16]. Sample size ranged from 7 to 68 individuals with a median of 18 (interquartile range 11-30). All males present in a herd were also enrolled in the study.

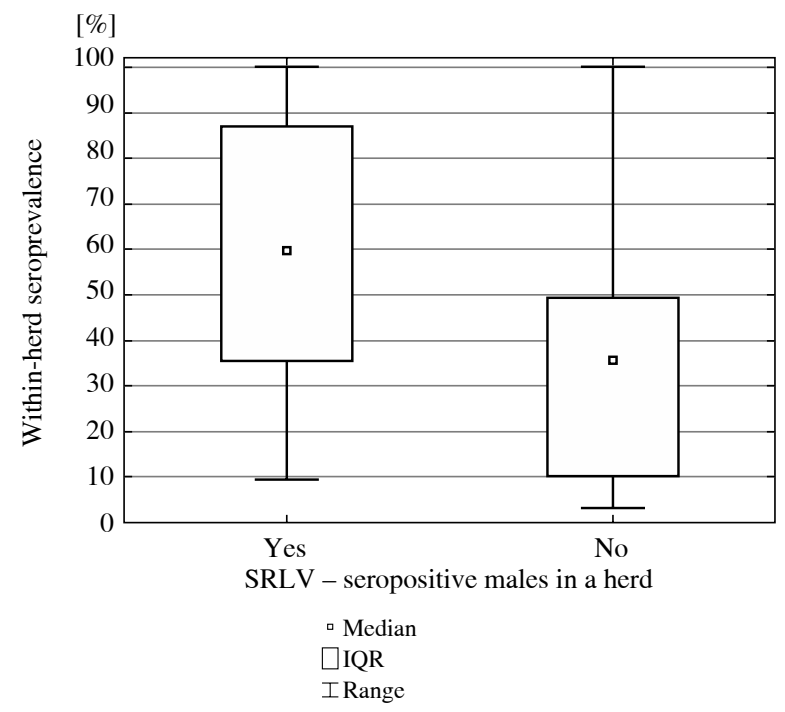

Fig. 1. Within-herd seroprevalence of SRLV infection with respect to the presence of SRLV-seropositive bucks in a herd
The animals were screened with one of three commercial immunoenzymatic tests: indirect ELISA Checkit CAEV/MVV (Dr. Bommeli AG, Bern, Switzerland) between 1996-2014, indirect Pourquier ELISA Maedi-Visna/ CAEV Serum Verification (Institut Pourquier, France) in years 2007-2010, and ID Screen ${ }^{\circledR}$ MVV-CAEV Indirect Screening ELISA (IDvet Innovative Diagnostics, France) between 2011-2012. To obtain true seroprevalence apparent seroprevalence was adjusted by the sensitivity and specificity of the ELISA test used. They were $84 \%$ and $100 \%$, respectively, for both the Bommeli and Pourquier ELISAs [17], and $91.7 \%$ and $98.9 \%$, respectively, for the ID Screen ELISA [18].

Standardized questionnaires were used to gather knowledge of 3 hypothesized herd-level confounding factors: number of years for which a herd had existed until testing (herd age), goat replacement from other herds in Poland and use of machine milking.

Hierarchical linear regression model was performed in three-level fashion: First, the herd age was forced into the model to control for the role of time as CAE is a slowly-spreading contagious disease and is likely to be more prevalent in older herds. Then, two potential confounding factors were entered into the model as dichotomous variables (goat replacement from other herds in Poland and machine milking). At the last level presence of SRLV-seropositive males was introduced. Factors were considered statistically significant if their $p$-value was $<0.05$.

Adjusted coefficient of multiple correlations $\left(\mathrm{R}^{2}\right)$ was a goodness-of-fit measure for the final model. Statistical analysis was performed in IBM SPSS Statistics 21.

\section{Results}

Within-herd seroprevalence of SRLV infection ranged from $9.7 \%$ to $100 \%$ in the herds where seropositive males were present (median of $60.1 \%$, interquartile range from $35.7 \%$ to $87.9 \%$ ) and from $3.4 \%$ to $100 \%$ in the herds were only seronegative males were kept (median of $35.8 \%$, interquartile range from $10.1 \%$ to $49.6 \%$ ) (Fig. 1).

Table 1. Results of the hierarchical linear regression analysis evaluating the relationship between the presence of seropositive males in a herd and within-herd seroprevalence adjusted by possible confounding factors

\begin{tabular}{|c|c|c|c|c|}
\hline Variable & $\begin{array}{l}\text { Regression coefficients } \\
\text { (95\% confidence interval) }\end{array}$ & $\begin{array}{c}\text { Standardized regression } \\
\text { coefficients }\end{array}$ & $\begin{array}{l}t \text {-statistics } \\
\quad(\text { df } 71)\end{array}$ & $p$-value \\
\hline Intercept & $19.15(2.90,35.41)$ & - & - & - \\
\hline Herd age $^{\dagger}$ & $0.83(-0.42,2.08)$ & 0.13 & 1.33 & 0.189 \\
\hline Machine milking $^{\dagger}$ & $12.15(-2.90,27.20)$ & 0.17 & 1.61 & 0.112 \\
\hline $\begin{array}{l}\text { Goat replacement from other herds } \\
\text { in Poland }{ }^{\dagger}\end{array}$ & $19.60(6.88,32.32)$ & 0.31 & 3.07 & 0.003 \\
\hline SRLV-positive male & $22.26(9.83,34.68)$ & 0.36 & 3.57 & 0.001 \\
\hline
\end{tabular}


Table 2. Change of coefficient of multiple correlations ( $\mathrm{R}^{2}$ change) associated with addition of subsequent variables to the hierarchical model

\begin{tabular}{|c|c|c|c|c|}
\hline Model & $\mathbf{R 2}$ & R2 change & F change $(\mathrm{df} 1, \mathrm{df} 2)$ & Significance of $F$ change \\
\hline $1^{\text {st }}$ level $^{\dagger}$ & 0.042 & 0.042 & $3.21(1,74)$ & 0.077 \\
\hline $2^{\text {nd }}$ level ${ }^{\ddagger}$ & 0.193 & 0.151 & $6.73(2,72)$ & 0.002 \\
\hline $3^{\text {rd }}$ level $^{\S}$ & 0.315 & 0.123 & $12.75(1,71)$ & 0.001 \\
\hline
\end{tabular}

${ }^{*}$ includes only intercept and herd age
machine milking and goat replacement from other herds in Poland added

s presence of SRLV-positive males in a herd added

Controlling for the herd age, machine milking and goat replacement from other herds in Poland, presence of SRLV-seropositive bucks proved to be an independent factor linked to the higher within-herd seroprevalence of SRLV $(p=0.001)$ (Table 1). SRLV infection of bucks accounted for $12 \%$ of the total variability of the within-herd seroprevalence (Table 2). The final model had an adjusted- $\mathrm{R}^{2}$ of $0.28(\mathrm{~F}(4,71)=8.18$, random error $=693.57$, $p<0.001)$.

\section{Discussion}

The study revealed that if all other confounding factors had remained constant the presence of seropositive males in a herd would have been associated with 22 -fold higher within-herd seroprevalence on average. The buck effect was difficult to evaluate quantitatively as the range varied from a 10 -fold to 35 -fold increase in within-herd seroprevalence. This may be because the time bucks remain in direct contact with female goats in Polish herds is usually restricted to the mating season and varies from 2 to more than 10 weeks. However, given that between-animal contacts are intensive and frequent in this time it is likely sufficient for SRLV transmission, although route of this transmission remains questionable.

Two out of three potential confounding factors which were forced into the model turned out to be insignificant - machine milking and the time for which a herd had existed until testing. However, there is important rationale for retaining each of them in the model. The role of milking practices in the spread of SRLV infection in a herd has been described [1] as well as a variety of possible mechanisms accounting for this route of transmission, including shared milking machines and backflow of milk into the teat during machine milking were proposed [7]. Even if machine milking had not proven statistically significant in our situation it was reasonable from the epidemiological standpoint to control for this variable in the model. The longer a herd exists the more likely the infection is to spill over into and spread within this herd. This conclusion holds only unless a CAE control program is being implemented which is indeed the case in Poland. Much better would be to take into account the time for which a herd had been infected until testing. However, no such data are available since no constant monitoring of this disease has ever been carried out. The time for which a herd had existed until testing (the herd age), may be considered as the best available estimate of the herd infection span. The most influential confounder was goat replacement from other herds in Poland which resulted in 20-fold increase of within-herd seroprevalence on average. This result was justified by the fact that three consecutive serosurveys carried out for last 20 years has shown that between-herd seroprevalence is high and tends to rise rather than decline [19]. Given that horizontal route plays an important role in SRLV transmission between animals purchase of infected goats precipitates infection spread and increases within-herd prevalence.

This study does not provide any evidence for sexual transmission of SRLV. Infected bucks may pass the virus in respiratory secretions like all other goats do. Nonetheless whether several weeks of direct contact are sufficient for respiratory SRLV transmission remains doubtful as all available studies indicate that horizontal spread of SRLV is a fairly slow process $[3,7]$. The study is also not able to determine the direction of the transmission - higher seroprevalence may result from the contact with infected males; on the other hand males may be seropositive due to contact with many infected does. However, sexual transmission of lentiviral infections is believed to occur much easier from males to females than vice versa, mainly due to higher risk of abrasions of female genital tract during sexual intercourse. Furthermore, although presence of SRLV-infected cells was demonstrated in the uterus and oviducts [20] no data on infection of the vagina or external genital organs are available.

Concluding, the study indicates that seropositive bucks may facilitate the spread of SRLV infection in goat herds and therefore their presence should be considered as a risk factor.

The authors declare no conflict of interest. 


\section{References}

1. Adams DS, Oliver RE, Ameghino E, et al. (1984): Global survey of serological evidence of caprine arthritis-encephalitis virus infection. Vet Rec 115: 493-495.

2. Peterhans E, Greenland T, Badiola J, et al. (2004): Routes of transmission and consequences of small ruminant lentiviruses (SRLVs) infection and eradication schemes. Vet Res 35: 257-274.

3. Kaba J, Bagnicka E, Czopowicz M, et al. (2011): Long-term study on the spread of caprine arthritis-encephalitis in a goat herd. Cent Eur J Immunol 36: 170-173.

4. Rowe JD, East NE, Thurmond MC, et al. (1992): Cohort study of natural transmission and two methods for control of caprine arthritis-encephalitis virus infection in goats on a California dairy. Am J Vet Res 53: 2386-2395.

5. Rowe JD, East NE, Franti CE, et al. (1992): Risk factors associated with the incidence of seroconversion to caprine arthritis-encephalitis virus in goats on California dairies. Am J Vet Res 53: 2396-2403.

6. Péretz G, Bugnard F, Calavas D (1994): Study of a prevention programme for caprine arthritis-encephalitis. Vet Res 25: 322-326.

7. Rowe JD, East NE (1997): Risk factors for transmission and methods for control of caprine arthritis-encephalitis virus infection. Vet Clin North Am Food Anim Pract 13: 35-53.

8. Lerondelle C, Greenland T, Jane M, Mornex JF (1995): Infection of lactating goats by mammary instillation of cell-borne caprine arthritis-encephalitis virus. J Dairy Sci 78: 850-855.

9. Al Ahmad MZ, Dubreil L, Chatagnon G, et al. (2012a): Goat uterine epithelial cells are susceptible to infection with Caprine Arthritis Encephalitis Virus (CAEV) in vivo. Vet Res 43: 5.

10. Travassos C, Benoît C, Valas S, et al. (1998): Detection of caprine arthritis encephalitis virus in sperm of experimentally infected bucks. Vet Res 29: 579-584.

11.Peterson K, Brinkhof J, Houwers DJ, et al. (2007): Presence of pro-lentiviral DNA in male sexual organs and ejaculates of small ruminants. Theriogenology 69: 433-442.

12. Al Ahmad MZ, Fieni F, Pellerin JL, et al. (2008): Detection of viral genomes of caprine arthritis-encephalitis virus (CAEV) in semen and in genital tract tissues of male goat. Theriogenology 69: 473-480.

13.Lamara A, Fieni F, Chatagnon G, et al. (2013): Caprine arthritis encephalitis virus (CAEV) replicates productively in cultured epididymal cells from goats. Comp Immunol Microb 36: 397-404

14. Turchetti AP, Paniago JJ, da Costa LF, et al. (2013): Distribution of caprine arthritis encephalitis virus provirus, RNA, and antigen in the reproductive tract of one naturally and seven experimentally infected bucks. Theriogenology 80: 933-939.

15. Al Ahmad MZ, Chebloune Y, Chatagnon G, et al. (2012): Is caprine arthritis encephalitis virus (CAEV) transmitted vertically to early embryo development stages (morulae or blastocyst) via in vitro infected frozen semen? Theriogenology 77 : 1673-1678.

16. Thrusfield M. Veterinary epidemiology. 3rd ed. Blackwell Publishing Ltd., UK, 2005.

17. Brinkhof J, van Maanen C (2007): Evaluation of five enzyme-linked immunosorbent assays and an agar gel immunodiffusion test for detection of antibodies to small ruminant lentiviruses. Clin Vaccine Immunol 14: 1210-1214.

18. Nowicka D, Czopowicz M, Mickiewicz M, et al. (2014): Diagnostic performance of ID screen MVV-CAEV Indirect
Screening ELISA in identifying small ruminant lentiviruses-infected goats. Pol J Vet Sci 17: 501-506.

19. Kaba J, Czopowicz M, Ganter M, et al. (2013): Risk factors associated with seropositivity to small ruminant lentiviruses in goat herds. Res Vet Sci 94: 225-227.

20. Fieni F, Rowe J, Van Hoosear K, et al. (2003): Presence of caprine arthritis-encephalitis virus (CAEV) proviral DNA in genital tract tissues of superovulated dairy goat does. Theriogenology 59: 1515-1523. 